\title{
Correction to: Global Justice Index Report
}

\author{
Yanfeng Gu ${ }^{1} \cdot$ Xuan Qin ${ }^{1} \cdot$ Zhongyuan Wang $^{1} \cdot$ Chunman Zhang $^{1}$. \\ Sujian Guo ${ }^{1}$ (D)
}

(c) The Author(s) 2020

\section{Correction to: Chinese Political Science Review https://doi.org/10.1007/s41111-020-00148-z}

The article "Global Justice Index Report", written by Yanfeng Gu · Xuan Qin . Zhongyuan Wang · Chunman Zhang and Sujian Guo, was originally published electronically on the publisher's internet portal on 4th June 2020 without open access. With the author(s)' decision to opt for Open Choice the copyright of the article changed on 27th July 2020 to (C) The Author(s) 2020 and the article is forthwith distributed under a Creative Commons Attribution 4.0 International License (https:// creativecommons.org/licenses/by/4.0/), which permits use, sharing, adaptation, distribution and reproduction in any medium or format, as long as you give appropriate credit to the original author(s) and the source, provide a link to the Creative Commons licence, and indicate if changes were made. The original article has been corrected.

The original article can be found online at https://doi.org/10.1007/s41111-020-00148-z.

\section{Sujian Guo}

sguo@fudan.edu.cn

1 Fudan Institute for Advanced Study in Social Sciences, Fudan University, Shanghai, China 